\title{
Surrogacy in China: Public Opinion, Litigations, and Court Rulings
}

\author{
Qian Tang ${ }^{1}$ \\ ${ }^{1}$ High School Affiliated to Shanghai Jiao Tong University, Shanghai, China \\ Correspondence: Qian Tang, High School Affiliated to Shanghai Jiao Tong University, Shanghai, 200439, China. \\ Tel: 86-180-160-41949. E-mail: tq_amytang@sina.com
}

Received: September 3, 2019

doi:10.5539/ass.v15n10p84
Accepted: September 16, 2019

Online Published: September 29, 2019

URL: https://doi.org/10.5539/ass.v15n10p84

\begin{abstract}
Culturally, commercial surrogacy has come to be viewed and criticized as immoral. Thus, many prefer it to be outlawed in China. At the same time, "to carry on the bloodline of the family" and having more children are also culturally celebrated in Chinese society. ${ }^{1}$ The two cultural traditions, together with the implementation and gradual revocation of the one-child policy in the 21 st century, have led to a dilemma modern Chinese parents are facing: more and more couples feel morally obligated to have more children after the revocation of the one-child policy but are too old to naturally reproduce. With the vagueness of regulations around commercial surrogacy in China, more couples have resorted to surrogacy in the past decade, which currently functions in a grey market. Within the unregulated market, both moral and legal concerns emerge. Through analysis of public opinion, litigations, as well as court rulings on surrogacy in China, this paper asks the following question: To what extent does the societal attitude in China on surrogacy align with that of litigations and court rulings on surrogacy in China? This paper hopes to provide insight into the Chinese surrogacy markets and responses from different actors within the process of surrogacy, leading to broader questions such as: How can litigations in China on surrogacy be improved? How can we ensure rights of all actors in a transaction concerning surrogacy? Should surrogacy be permissible at all? These are relevant questions relating to the structural violence prevalent in the seemingly peaceful modern China and have an impact on the direction of future feminist studies.
\end{abstract}

Keywords: surrogacy, China, litigation, public opinion

\section{Introduction}

The way children can enter a family has radically changed with the development of technology. Especially among upper class families around the globe, medical technologies such as in vitro fertilization and embryo transfers have sometimes replaced the traditional way of bearing children. Wealthy families are now more likely to select surrogacy as a means of acquiring children with whom they have a genetic tie. ${ }^{2}$

There are two main types of surrogacy. The first is altruistic surrogacy, a form of surrogacy in which no commercial transaction is involved. A woman agrees to carry a child for the intended parent and give birth to that child. The child may or may not be genetically related to the person giving birth. The second type is gestational surrogacy, which is the most common form of surrogacy today. ${ }^{3}$ The woman carrying the child is paid by the intended parents, usually via a third party. A pregnancy labor contract is signed before the woman is implanted with the fetus. The child the woman carries is usually not genetically related to her.

Though altruistic surrogacy can leave many loopholes for exploitation ${ }^{4}$, gestational surrogacy is the more controversial type and will be the focus of this paper. Though commercial surrogacy, especially transnational surrogacy (when the transaction involves actors of different nationalities, usually the surrogate mother and the commissioning parents), has always been the subject of heated academic discussion, there has rarely been research specifically focusing on China and its surrogacy market in the modern era, even though China has gone

\footnotetext{
${ }^{1}$ Peng Yusheng. (2010). When Formal Laws and Informal Norms Collide: Lineage Networks versus Birth Control Policy in China. The University of Chicago Press, 3(116), 770.

${ }^{2}$ Winddance Twine France, Outsourcing the Womb: Race, Class, and Gestational Surrogacy in a Global Market, 2nd ed. (New York: Routledge, 2015), preface.

3 Sally Howard. (October 20, 2014). Taming the International Commercial Surrogacy Industry. British Medical Journal, $349,3$. https://doi.org/10.1136

${ }^{4}$ France, Outsourcing the Womb, 13.
} 
through drastic economic and structural changes in recent decades and has unique reproduction policies. What's more, research on surrogacy-related cases in China has been extremely limited, so that even if people's lives have already been impacted by such legislation, the general public is not obtaining a clear understanding of law and surrogacy-related regulations. As a result, this paper focuses on the Chinese surrogacy market, the relevant legislation and court practices, as well as public opinions around surrogacy to provide an overview of surrogacy in China.

This paper will answer the question: To what extent does societal attitude in China on surrogacy align with that of litigations and court rulings on surrogacy in China? Following this introduction, this paper will delve first into a literature review, in which an overview of the reproduction status quo in China along with legislative practices will be provided, then the methodology of the research, followed by the obtained data and related analysis, and the conclusion. In the analysis section, this paper will ultimately show that litigations on surrogacy in China mostly condemn surrogacy as immoral, but the regulations are vague. Due to this vagueness, court rulings usually defer to contract laws and genetic relationships. On the surface, public opinion in China complies with the litigations and court rulings; however, in practice, surrogacy still serves as an option for reproduction with a booming underground market, while surrogate mothers are largely under-represented by the media and academic researchers. Though litigations and court rulings are against surrogacy as a whole, it is also worth noting that the current surrogacy legislation is ineffective, thus providing incentive for surrogacy companies to operate and develop.

\subsection{Litigations on Surrogacy in China}

Chinese law does not explicitly prohibit or permit surrogacy practices. According to Article 3 in Administrative Measures for Assisted Reproductive Technology published in 2001, it is forbidden in China to "buy or sell gametes, zygotes, and embryos in any form," and "Medical institutions and medical personnel must not implement any form of surrogacy technology." However, in December 2015, the Standing Committee of the National People's Congress removed this part of the article ${ }^{6}$, implying an attitude shift in the Chinese government. Nevertheless, Subsection 5, Part 3 of the Ethical Principles of Assisted Reproductive Technology and Human Sperm Banks, also published in 2001, still defines any surrogacy technology as illegal, prohibiting medical staff from performing surrogacy procedures. The changes to one document but not the other create confusion.

Regardless of the legislation, the publications by the Ministry of Health only carry out administrative sanctions, which means that any fines only fall on the medical staff but not the others involved; in other words, the commissioning parents, the institution (if not an officially registered medical agency), and the surrogate mother will not bear any criminal liabilities ${ }^{7}$. While institutions can still practice surrogacy under current Chinese legislation, the validity and legal issues revolving around surrogacy usually depend on the content of surrogacy contracts, or the interpretation of such contracts by the court. This will be further explained in the next section.

\subsection{Legislative Practices Regarding Surrogacy in China}

In terms of contract laws and court rulings regarding surrogacy contracts, the court usually rules according to the General Principles of the Civil Law of the People's Republic of China, in which Article 55 states that "A civil juristic act shall not violate the law or the public interest. ${ }^{8}$ " However, "public interest" is not clearly defined in the article; in other words, the interpretation of the law tends to depend on court traditions and the personal interpretation of the judge. One common controversy concerning commercial surrogacy is whether the surrogate mother can be seen as being paid by accepting the egg from the intended mother (or her own egg) or because of her gestational service. If the surrogate mother can be seen as merely providing a gestational service, then this person is not involved in the crime of transacting human gametes and human embryos. Practically, such a line of argument, if employed successfully, can get around the legal prohibition.

Of the five cases presented in The Analysis of Surrogate Dispute Case Report in Our Country, which was conducted in 2014 by Menglu Li, two are cases on sole care and control (disputes over the custody of the

\footnotetext{
${ }^{5}$ The Ministry of Health. Human Assisted Reproductive Technology Management Measures. Human Assisted Reproductive Technology Management Measures. Retrieved July 26, 2019, from http://www.gov.cn/fwxx/bw/wsb/content_417654.htm

${ }^{6}$ Mi Liu. On the Judicial Validity of Surrogacy Contracts - from the Perspective of Jeremy Bentham's Utilitarianism. May 2019, 20

${ }^{7}$ Vera Raposo \& U Sio Wai. (2017). Surrogacy in Greater China: The Legal Framework in Taiwan, Hong Kong, Macao, and Mainland China. Pacific Basin Law Journal, 34(2), 145.

8 National People's Congress. (1986). General Principles of the Civil Law of the People's Republic of China. http://www.china.org.cn/china/LegislationsForm2001-2010/2011-02/11/content_21898337.htm
} 
children), one is on visitation (whether the person has the right to visit the children), one is on parenthood, and one is on compensation regarding the contract. For the cases on sole care and control, both court decisions rendered the surrogacy contract invalid and claimed sole care and control of the child belonged to the intended parents, for the reasons that the child was genetically related to the intended parents and they were more economically capable of raising the child. ${ }^{9}$ In terms of the case on visitation, the surrogate mother was allowed the right to visit the child because she was the biological mother of the child ${ }^{10}$. In the case on parenthood, the twin children were genetically related to the intended father but not the mother, and the dispute happened between the parents of the intended father (the twins' grandparents on father's side) and the intended mother after the intended father's death. The court first rendered the surrogacy contract illegal and thus invalid. However, the court decided that the grandparents should get custody of the twins because they were genetically related, but then later overturned the verdict and identified the intended mother as holding parenthood for the twins because she could be considered their adoptive parent ${ }^{11}$. In the case on compensation, the surrogate mother refused to give the child to the intended parents, arguing that the pay for surrogacy was insufficient. This time, the court recognized the surrogacy contract as valid and thus no further reimbursement was to be given to the surrogate mother. Since the surrogate mother was not the genetic mother of the child, the court ruled that she did not have parenthood over the child. ${ }^{12}$

Through the analysis of these different surrogacy cases, Menglu Li concluded that the central considerations for court decisions are the validity of surrogacy contracts and the biological relationship between the different actors in the case. ${ }^{13}$ While some court decisions rendered the surrogacy contract as valid, most of the court decisions identified it as impermissible and thus invalid.

In another journal, Surrogacy Litigation in China and Beyond, author Chunyan Ding examines judicial solutions to surrogacy disputes through a case study, using ten cases that took place in China from 2004 to 2012. Out of the ten cases, six are on sole care and control, two are on visitation, one is on parenthood, and one is on breach of surrogacy contract. ${ }^{14}$ In these ten cases, Ding makes a distinction from previous analysis by arguing attorneys can and had exploited a loophole in surrogacy contracts involved in the legal disputes, contending that it should be held partially invalid; in other words, "the contractual clause on sole care and control of the surrogate child remained valid." surrogacy in these cases, the application of surrogacy laws in litigations in China is inconsistent, and few courts have given clear legal definitions on the exact legal clauses ${ }^{16}$.

\subsection{Chinese Culture on Reproduction and Gender Roles}

Regardless of legal views on reproduction, Chinese society also has its own interpretation of reproduction that is deeply culturally rooted. It is important for Chinese families to carry on the family bloodline, and this tradition puts the patrilineal system at the core of Chinese family and gender values. ${ }^{17}$ The patrilineal system contributes to Chinese tradition in three ways: it emphasizes the male line of descent, which is relatively more valuable in an ancient agricultural society; it regulates the family's economic relationship in terms of inheritance; and it is defines family boundaries. ${ }^{18}$

Multiple factors have influenced these traditions, depending on region and socioeconomic status. Through Deng Xiaoping's policy on reform and opening up starting from $1978^{19}$, Chinese society became more exposed to the global market, with the big cities at the forefront and thus more influenced by western ideas of individualism and

\footnotetext{
${ }^{9}$ Menglu Li. (2017). The Analysis of Surrogate Dispute in Our Country. Guangdong University of Finance and Economics, 3.

${ }^{10} \mathrm{Li}$, The Analysis of Surrogate Dispute in Our Country, 5.

${ }^{11} \mathrm{Li}$, The Analysis of Surrogate Dispute in Our Country, 4.

${ }^{12} \mathrm{Li}$, The Analysis of Surrogate Dispute in Our Country, 3-4.

${ }^{13} \mathrm{Li}$, The Analysis of Surrogate Dispute in Our Country, 21.

${ }^{14}$ Chunyan Ding. (January 8, 2015). Surrogacy Litigation in China and Beyond. Journal of Law and Biosciences, 33-35, 37. https://doi.org/10.1093/jlb/lsu036

15 Ding, Surrogacy Litigation in China and Beyond, 41.

${ }^{16}$ Ding, Surrogacy Litigation in China and Beyond, 43.

${ }^{17}$ Yang Hu \& Jacqueline Scott. (n.d.). Family and Gender Values in China: Generational, Geographic, and Gender Differences. Journal of Family Issues, 4. https://doi.org/10.1177/0192513X14528710

${ }^{18} \mathrm{Hu}$ and Scott, Family and Gender Values in China: Generational, Geographic, and Gender Differences, 4.

${ }^{19}$ Deng presided over the Chinese government during a period of enormous economic change, when he enacted the policy "reform and opening up." Under his leadership, these reforms transformed the economic system in China, bringing the country out of isolation and into the modern world economy.
} 
feminism than the inner cities and provinces. As a result, coastal and larger cities in China are generally more equal in terms of gender. The other factor is the one-child policy. While some argue that the policy liberated women from housework, others contend that the policy has led Chinese women further into childcare. ${ }^{20}$ The next section will talk more about the one child policy in China. Another policy that contributes to current views on gender in China is the Hukou policy. This policy mandated housing registration throughout the country in order to control population mobility and secure enough labor for each sector of production. ${ }^{21}$ The distinction between urban and rural was further exacerbated by this policy.

Gender roles and perceptions on reproduction within Chinese society vary. We cannot draw a simple conclusion on the general public opinion towards reproduction, but it is reasonable to conclude that traditional gender roles still play a prominent part in modern Chinese society.

\subsection{An Overview on the One-Child Policy in China}

The Chinese government initiated the one child policy in 1980, restricting the number of children a family could have. Though slightly different rules applied to different regions, most families could have no more than two children. ${ }^{22}$ The one child policy has yielded significant results in the years of its implementation; according to a 2010 Population Census, the average woman at the time only had 1.18 children. In 2013, China launched the two-child program, according to which if one of the parents was a single child, then the couple could have a second child without paying an extra fee. However, the two-child policy was not met with huge success; according to a press conference held by the National Health and Family Planning Commission in July 2015, only $13 \%$ of the population who were eligible for a second child had a second child in accordance with the new policy. The British Medical Journal reported in 2006 that all age groups and social classes in China prefer to have two children or fewer. ${ }^{23}$ As of January 1, 2016, the Chinese government allowed all Chinese couples to have two children.

The impact of the one-child policy is two-fold: not only has it influenced gender roles, but it has also altered the surrogacy market in China. In terms of its impact on fertility, with each successive birth cohort being smaller and women tending to marry men older than themselves, there are fewer potential brides. ${ }^{24}$ Together with the tradition of favoring boys over girls, ultrasound technology and easy access to abortions, the one child policy has further skewed the gender ratio. ${ }^{25}$ With the revocation of the one-child policy and the increasing infertility rate leading to the rise of the surrogacy industry, the problem around the gender ratio was further exacerbated. The parents that were most impacted by the one child policy - in other words, those born in the 1960s and 1970s - have found themselves able to have a second child under the new government policy when they are in their fifties or sixties, a time when it is relatively more dangerous to give birth or is biologically impossible. With the development and increasing accessibility of in vitro fertilization, the demand for surrogacy services has risen and the supply has increased to match.

\subsection{An Overview of the Status Quo of Reproduction in China}

In May 2019, a Chinese law review journal published a report on surrogacy as well as facts and statistics on reproduction. The report shows one in eight couples in China face reproductive concerns. ${ }^{27}$ Throughout the past 20 years, the infertility rate in China has grown from $3 \%$ to approximately $12.5-15 \%$. Some argue that increasing environmental degradation and other forms of pollution are responsible for the growing infertility rate. ${ }^{28}$ Statistics show that out of all the cases of infertility, $50 \%$ can be credited to the female, $30 \%$ to the male, $10 \%$ to both parties, and $10 \%$ to unidentified reasons. ${ }^{29}$

\footnotetext{
${ }^{20} \mathrm{Hu}$ and Scott, Family and Gender Values in China: Generational, Geographic, and Gender Differences, 6.

${ }^{21} \mathrm{Hu}$ and Scott, Family and Gender Values in China: Generational, Geographic, and Gender Differences, 6.

22 The one-child policy mandated the maximum number of children a family could have. In the early phase of its implementation, most families could only have one child, with the exception families in an ethnic minority in China, or the first child of the family having disabilities. Over time, the one-child policy was gradually revised. In 2013, China launched the two-child policy, and in 2016, China revoked all policies regarding the number of children a family can have.

23 Malcolm Potts. (August 19, 2006). China's One Child Policy. British Medical Journal, 33(7564), 361.

24 Potts, China's One Child Policy, 361.

25 Potts, China's One Child Policy, 361.

${ }^{26}$ Ding and Hesketh found a ratio of male to female births of 1.15 rising to 1.23 during 1996 and 2001 , the years during which the one child policy was implemented.

${ }^{27}$ Mi Liu. On the Judicial Validity of Surrogacy Contracts - from the Perspective of Jeremy Bentham's Utilitarianism. May $2019: 21$.

28 France, Outsourcing the Womb, preface.

${ }^{29}$ Liu, On the Judicial Validity of Surrogacy Contracts - from the Perspective of Jeremy Bentham's Utilitarianism, 21.
} 


\subsection{Current Academic Debates Regarding Surrogacy}

Feminist scholars have been discussing the topic of surrogacy for a long time without reaching a widely accepted conclusion. Those providing justification for surrogacy include feminist scholar Andrea Whittaker, who contends that surrogacy, especially transanational surrogacy, can be explained by certain ideologies and beliefs that manifest locally. ${ }^{30}$ In Thailand, such belief is rooted in the religion of Theravada Buddhism - the religious notion of pregnancy as a meritorious act by women which provides a moral framing for the surrogacy relationship and interprets surrogacy with approval because of the positive karmic consequences. ${ }^{31}$ Other pros of surrogacy include what is described by many surrogacy companies as more variety of reproductive choices and freedom of choice for women.

On the other hand, as contended by feminist scholar Khader, when considering surrogacy one needs to see how factors like race and class intensify gender oppression, and that the general lack of healthcare and enforced national standards within the surrogacy market has increased the risks of surrogate bodily and psychological harm. ${ }^{32}$ In the book Outsourcing the Womb, author France Winddance Twine points out that the global market for fertility therapies is structured, like access to any infrastructure, by race, class, and economic disparities. ${ }^{33}$ Twine also discusses how some see surrogacy as taking advantage of women's lack of autonomy and reducing women's autonomy during pregnancy (because many surrogate mothers are forced into abortion), or trying deceive women that surrogacy involves performing a loving act for the intended parents. ${ }^{34}$

Other ethical concerns regarding being a surrogate mother under the status quo are further described by Anton van Niekerk and Liezl van Zyl, who draw an analogy between surrogacy and prostitution. Niekerk and Zyl argue that both surrogacy and prostitution employ a "similar form of exploitation", and in both cases one's physical service is offered. ${ }^{35}$ Niekerk and Zyl think surrogacy should be illegal and argue that "surrogacy is wrong because it commodifies women's reproductive labor" with surrogate mothers required to repress parental love for the child and the market's manipulation and denial of legitimacy to the surrogate mother's evolving perspective on her own pregnancy, which makes surrogate mothers "an alienated population". ${ }^{36}$

\section{Methodology}

In this paper, I will analyze relevant posts on surrogacy on some of the most popular mommy blogs ${ }^{37}$ in China to gather public opinions around the issue of surrogacy. I selected the mommy blogs to be discussed by entering "most popular mommy blogs" in Chinese into Google's search engine, and clicked into the site "China Webmaster," in which mommy blogs are ranked by a comprehensive analysis for their popularity. ${ }^{38}$ In order to obtain a well-rounded review of public opinion on surrogacy, I searched for the word "surrogacy" in the top ten mommy blog websites provided. Among those that yielded results, I picked the top three in the ranking for further analysis: PCBaby, Mama, and Ci123. ${ }^{39}$ Among the three selected sites, I again typed in "surrogacy" to search within these websites. Among all the results, I selected the blog posts and questions that received more than five responses/votes in hope of obtaining an unbiased overview of public opinions.

The screenshot of the China Webmaster rankings from July 28, 2019 is provided below (Figure 1).

\footnotetext{
${ }^{30}$ Andrea Whittaker. (Fall 2014). Merit and Money: The Situated Ethics of Transnational Commercial Surrogacy in Thailand. International Journal of Feminist Approaches to Bioethics, 7, 100.

${ }^{31}$ Whittaker, Merit and Money: The Situated Ethics of Transnational Commercial Surrogacy in Thailand, 111.

${ }^{32}$ Serene J. femi. (Spring 2013). Intersectionality and the Ethics of Transnational Commercial Surrogacy. International Journal of Feminist Approaches to Bioethics, 6, 72.

${ }^{33}$ France, Outsourcing the Womb, 70.

${ }^{34}$ France, Outsourcing the Womb, 73-74

${ }^{35}$ Anton van Niekerk and Liezl van Zyl. (December 1995). The Ethics of Surrogacy: Women's Reproductive Labour. Journal of Medical Ethics, 21, 345 .

${ }^{36}$ Niekerk and Zyl, The Ethics of Surrogacy: Women's Reproductive Labour, 346.

${ }^{37}$ Mommy blogs are social media platforms on which parents (mostly mothers) share their experiences of raising children. Mommy blogs are usually characterized by their different focuses concerning children's growth.

${ }^{38}$ The factors that would affect this ranking include Alexa ranking (the international web ranking), baidu popularity (baidu is the most popular Chinese search engine, given that Google is blocked in mainland China), PageRank, popularity on mobile devices, and the standard deviation of ranking over time.

${ }^{39}$ Some of the mommy blogs do not have a forum/blog post specifically concerning surrogacy, while some others require membership (invitation from another user) to access information.
} 

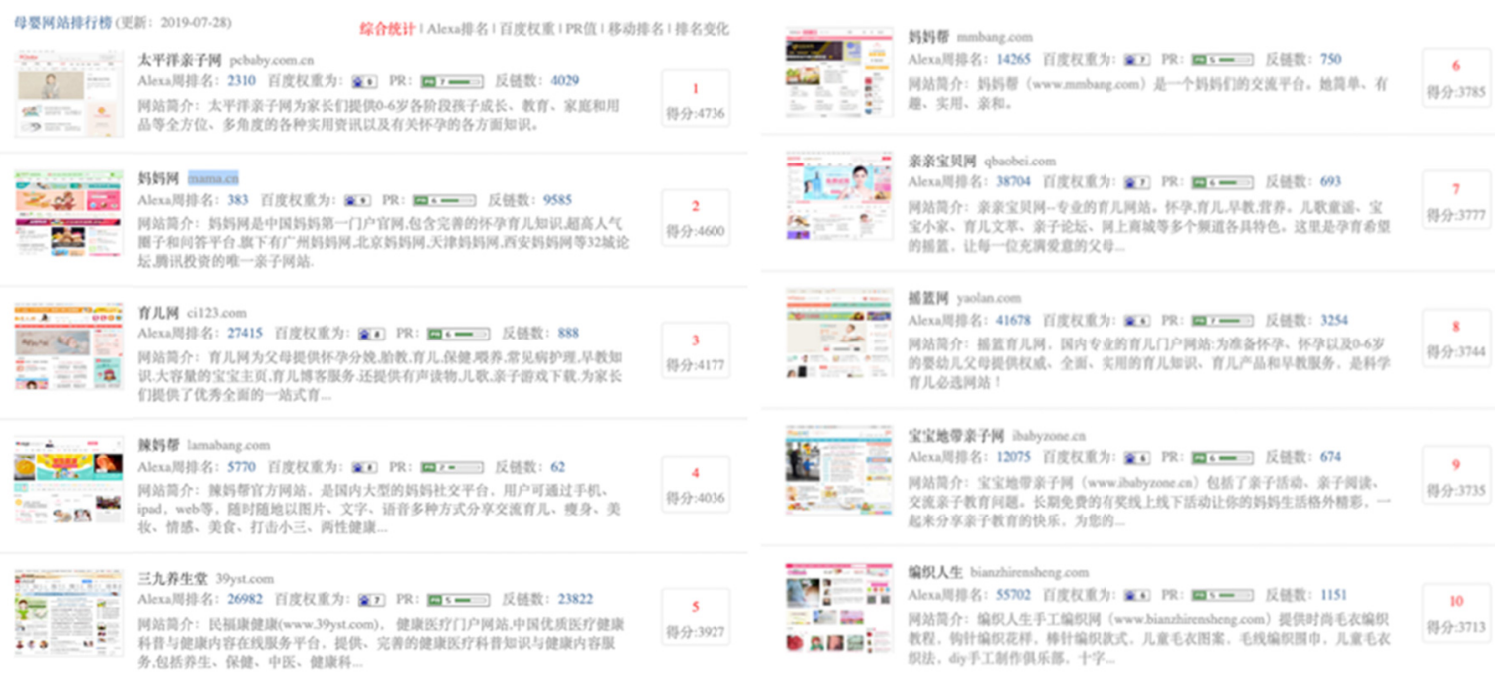

Figure 1.

Other than mommy blogs, interviews conducted by other news outlets will also serve as a primary source for analysis. The interviewees include prospective commissioning parents, surrogacy companies' leaders, and occasionally, the surrogate mothers. To search for those news articles, I searched for "surrogacy" in Chinese on both the Chinese search engine Baidu.com and the more international search engine Google.com in order to obtain both an international perspective and a Chinese perspective regarding surrogacy. The different results yielded by the two websites will also be discussed in the following analysis.

\section{Data and Analysis}

I will discuss public opinion regarding surrogacy from three different angles, in the order of commissioning (intended) parents, surrogate mothers, and the industry as a whole.

For the analysis of the intended parents, I will start the discussion by analyzing different mommy blogs and interviews.

\subsection{PCbaby}

Operating under the PC Group (a company called Pacific Online), the PCBaby discussion platform was founded in 2007 and has focused on the mother-baby market since then. Most of the discussion on the platform revolves around children from 0 to 6 years old. ${ }^{40}$

The discussions on the platform are mostly centered in the "forum" section and the "quick ask" section. Entering the word "surrogacy" in the forum section, I found that the controversy concerning surrogacy can be categorized into two parts - legality and acceptability of commercial surrogacy.

Regarding legality, the host of the blog discussion puts forward a question asking whether surrogacy is legal in China. ${ }^{41}$ The blog post received 24 responses by 17 users, among which 6 asserted that surrogacy is illegal, 3 claimed it is legal, and 8 did not provide a clear "yes" or "no" to the question. Among the 8 indefinite answers, 3 viewed surrogacy as negative: one condemned surrogacy as "unfair" (the user did not specify why surrogacy is "unfair"); one argued that the child does not "fully belong to the intended parents as the fetus would absorb nutrients from the surrogate mother"; and one contended that adoption is a better solution for having a child. Another 3 of the 8 viewed surrogacy as positive: two of them regarded surrogacy as a private issue between the surrogate mother and the commissioning parents and thus "none of the business with legislation"; and the third emphasized the "will to have a baby", justifying surrogacy by looking at practices of celebrities who also sought surrogacy as an alternative.

Another blog post conducted a vote surveying the acceptability of surrogacy, dividing the answer categories into "fully acceptable", "unacceptable, even if unable to bear a child", "unimaginable, have never thought about surrogacy", and "other". ${ }^{2}$ The blogger gave a specific premise for this question: when the mother is biologically

\footnotetext{
40“'Introduction - PCbaby - Pacific Online," accessed August 24, 2019, https://corp.pconline.com.cn/english/index-baby.htm

${ }^{41}$ Surrogacy, is it feasible and legal?_Forum_PCBaby. Accessed August 24, 2019, https://bbs.pcbaby.com.cn/topic-569003.html

${ }^{42}$ Can you accept surrogacy?_Women's mood_Forum_PCBaby. Accessed August 24, 2019, https://bbs.pcbaby.com.cn/topic-371782.html
} 
able to bear a child but chooses surrogacy for the sake of convenience (the blogger used the term "convenience" but later specified that the mother resorted to surrogacy out of career and monetary concerns). 16 people participated in the vote, among which 7 chose "unacceptable, even if unable to bear a child", 8 chose "unimaginable, has never thought about surrogacy", 1 chose "other", and none of the participants chose "fully acceptable". In the comment area of the blog post, 17 users provided their opinions on surrogacy, with 14 against surrogacy, 2 with unclear attitudes (e.g. "I don't have an opinion"; "never thought of this before"), and 1 "accepting but not promoting" surrogacy.

It can be concluded from the above data that generally mothers are not well exposed to legislation concerning surrogacy. Only about one third of the responses confirmed surrogacy as illegal. Another one sixth of the respondents regarded surrogacy as legal, which is the direct opposite of current Chinese legislation, with the rest of the responses unclear on surrogacy. This may explain why the demand for surrogacy is currently growing in China: the families may be first unaware of the illegality of surrogacy itself, and when uncertain on legislation, most view surrogacy as an acceptable alternative when dealing with infertility. Regarding societal attitudes, users of PCBaby showed clear negative attitudes when the intended parents are fertile; however, when regarding surrogacy in general, the "unclear about legislation" population demonstrated a relatively neutral attitude toward surrogacy, with the same number of participants viewing surrogacy as positive and negative.

Regardless of users' attitudes toward surrogacy, one thing worth noting from PCBaby is that all users deem "having a baby" as a reasonable and legitimate concern. Most are against surrogacy when the intended parents can naturally reproduce, and even with those who cannot, the objectors suggested the alternative of adoption. Many of them also mentioned how "having a child is a private business" and using the mother's own flesh is important during pregnancy, thus implying that surrogacy is a last resort.

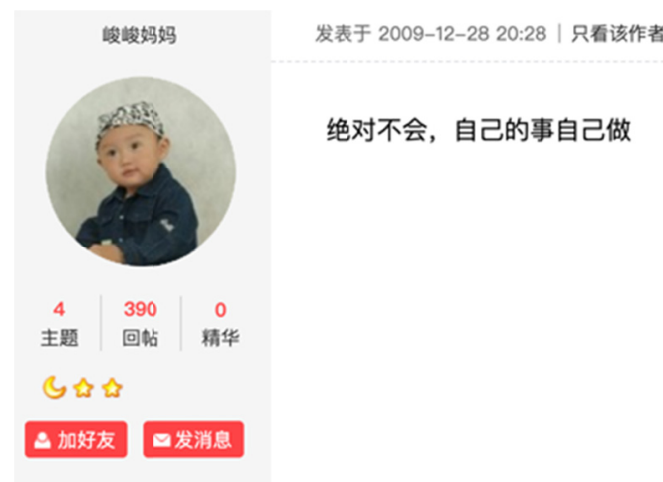

Figure 2.

Figure 2 is a screenshot of a user's response concerning the acceptability of surrogacy. The user states, "definitely not, I would prefer to deal with my own business."

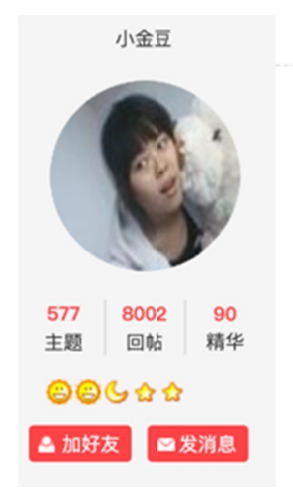

发表于 2010-07-29 08:45 | 只看该作者

14 楼

可是小孩子生长过程中也要吸收别人的东西。我感觉那孩子不完全是你们的

Figure 3.

Figure 3 is a screenshot of a user's response concerning the legality of surrogacy. The user states, "but the child needs to absorb nutrients from others; I feel that the child is not completely yours."

\subsection{Mama}

Founded in 2006, Mama is the largest parent-child social networking platform in China, on which mothers can share their maternal experiences. 
On entering "surrogacy" in a search of this website, there is only one blog post that has more than five responses around this topic. Titled "Women as Child Bearing Machines? Do you support legalization of surrogacy?", the blog post provides a screenshot of two news outlets, one reporting on the removal of Article 3 in Administrative Measures for Assisted Reproductive Technology (as mentioned earlier in this paper), and the other reporting on doctors advocating for the legalization of surrogacy due to low fertility rates. Following the screenshots, the blog post (Figure 4) then argues the pros (e.g. babies can enrich families facing infertility) and cons (e.g. human trafficking, the alternative of adoption, legal concerns) of surrogacy, with a clear bias towards the negative side of surrogacy.
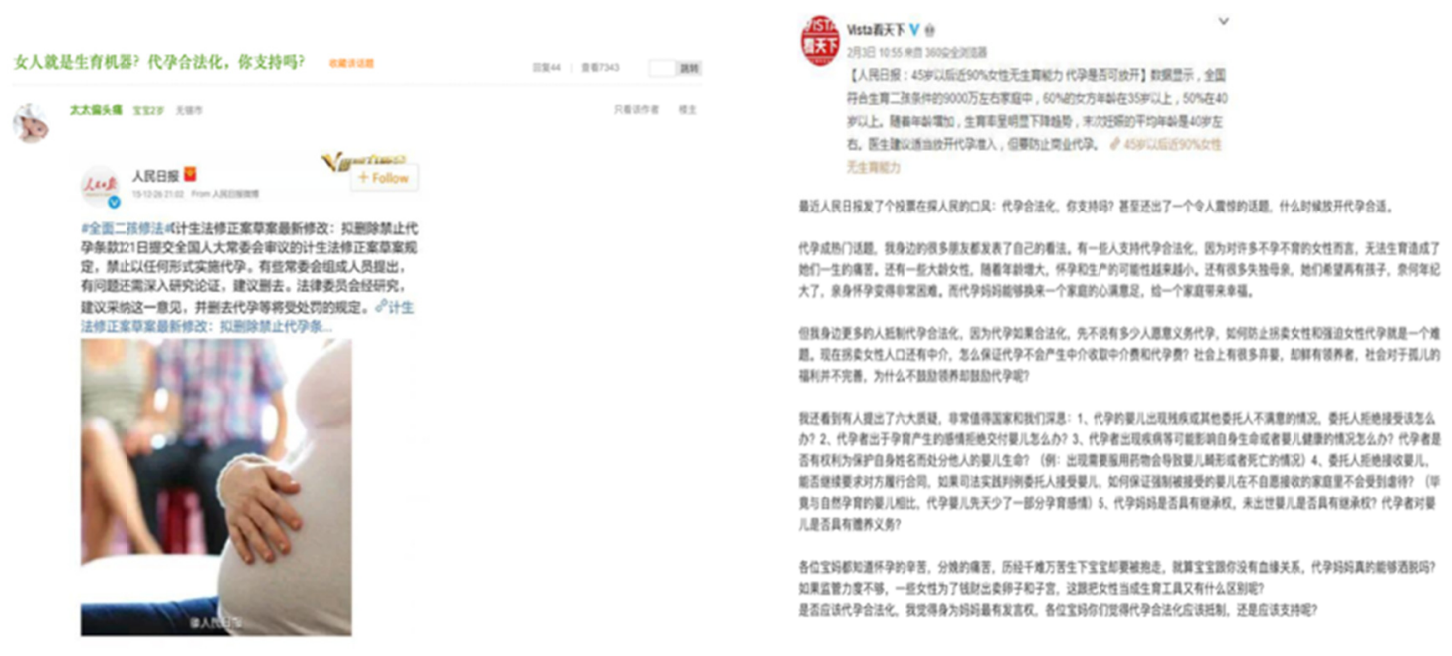

Figure 4.

The blog post received 44 responses from 40 users. Among the 44 responses, 6 are explaining the definition of commercial surrogacy. Among the other 38 responses, only 3 are in support of surrogacy, one for the reason that it is exhausting to bear babies as one gets older (with the revocation of the one-child policy, many of the mothers wanting a second child are in their 40s or 50s), one for the reason that some wives are forced to divorce their spouses due to infertility, and one does not provide a reason for their support. For those voicing opposition to the legalization of surrogacy, reasons vary. Concerns can generally be sub-divided into 5 categories: worries about human trafficking (that surrogate mothers are forced into this business), mother-child bonding during pregnancy, commidification of women, potential family disputes, and difficulty regarding legal supervision. Though supporters and opposers have different viewpoints, both sides extend their arguments under the premise of "for the good of women". Regardless of whether they view women as the relatively more vulnerable group in society or as equals to men, they see their arguments as supporting the advancement of women, either for higher social status or simply avoiding harm. For those advocating for having children as a necessity to family stability, even they are essentially arguing for the betterment of women - that to them, though children are indeed important in and of themelves, they are often an integral factor for women to maintain a decent status within a household, as they ensure women have accomplished the traditional goal of "carrying on the family bloodline". Though a bias towards negative impressions of surrogacy can be interfered from the blog poster's framing of their post, in general, users on the Mama platform see surrogacy as negative and hard to regulate, and are mostly against the legalization of surrogacy. Thus it is reasonable to conclude that on the surface level, public opinion in China does comply with the litigations and court rulings, regarding surrogacy as in a negative light.

\subsection{MMBang}

Founded in 2003, MMBang centers its service around families with children from 0 to 6 years old. The website indicates its mission is to promote independent thinking for a new generation of mothers, advocating for motherhood as an identity instead of a defining career. MMBang also claims to be a platform for understanding and supporting new moms by providing expertise and services. ${ }^{43}$

Discussions on MMBang can generally be divided into three types: opinions on surrogacy as a whole, acceptability of the occupation of surrogate mother, and legalization of surrogacy.

In a post concerning opinions regarding surrogacy as a whole, the blog poster provides a brief description of the

\footnotetext{
${ }^{43}$ About MMBang_MMBang. Accessed August 24, 2019, https://www.mmbang.com/about/about
} 
definition of surrogacy, warning of ethical concerns regarding surrogacy (without specification of these conerns), and quotes a Wuhan surrogacy bussinessman that a sucessful surrogacy service usually costs about 150,000 rmb (approximately \$21,428). ${ }^{44}$ This blog post received 41 responses. Unlike other blog posts among which participants mostly imagine themselves as commissioning parents, respondents under this post imagined themselves as either the surrogate mothers or complete outsiders.

A summary of the responses is shown below (Figure 5 and Figure 6):

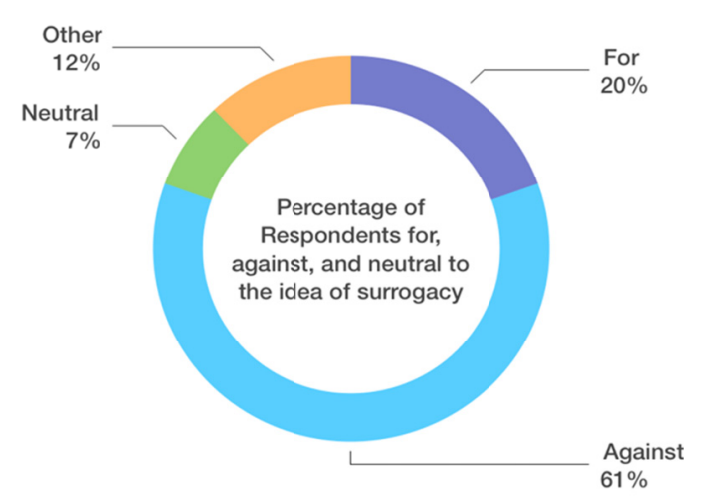

Figure 5. Made by the author, this graph summarizes attitudes of 41 respondents towards surrogacy

$\begin{aligned} & \text { Percentage of Respondents for, against, and neutral to the } \\
& \text { idea of surrogacy }\end{aligned}$
\begin{tabular}{|l|c|}
\hline GENERAL ATTITUDE & NUMBER OF PARTICIPANT \\
\hline For & 8 \\
Against & 25 \\
Neutral & 3 \\
\hline Other & 5 \\
\hline
\end{tabular}

Figure 6. Made by the author, this graph specifies the number of participants in an MMBang blog post showing attitude of support, opposition, and neutrality towards surrogacy

Among the participants in the category of "other", one person argued that $150,000 \mathrm{rmb}$ is not enough for one to be a surrogate mother, and another two clarified the idea of surrogacy and addressed minor points from others' responses.

Among those who were for the idea of surrogacy, reasons for support vary, as shown in the following graph (Figure 7):

\section{Reasons Provided by Supporters}

\begin{tabular}{l|c|}
\hline REASONS FOR SUPPORT & NUMBER OF PARTICIPANT \\
\hline $\begin{array}{l}\text { Financial concerns of surrogate } \\
\text { mothers }\end{array}$ & 1 \\
\hline Having a baby is to help a family & 2 \\
\hline $\begin{array}{l}\text { Only altruistic surrogacy is } \\
\text { acceptable }\end{array}$ & 1 \\
\hline $\begin{array}{l}\text { Only supervised surrogacy is } \\
\text { acceptable }\end{array}$ & 4 \\
\hline
\end{tabular}

Figure 7. Made by the author, this graph shows reasons of support among the 8 participants who demonstrated a positive attitude towards surrogacy in their responses to an MMBang blog post

\footnotetext{
${ }^{44}$ [News on Trend]How do you view the surrogacy industry?_MMBang in Suzhou_ MMBang. Accessed August 24, 2019, https://www.mmbang.com/suzhou/bang/6872673\#comment_enter
} 


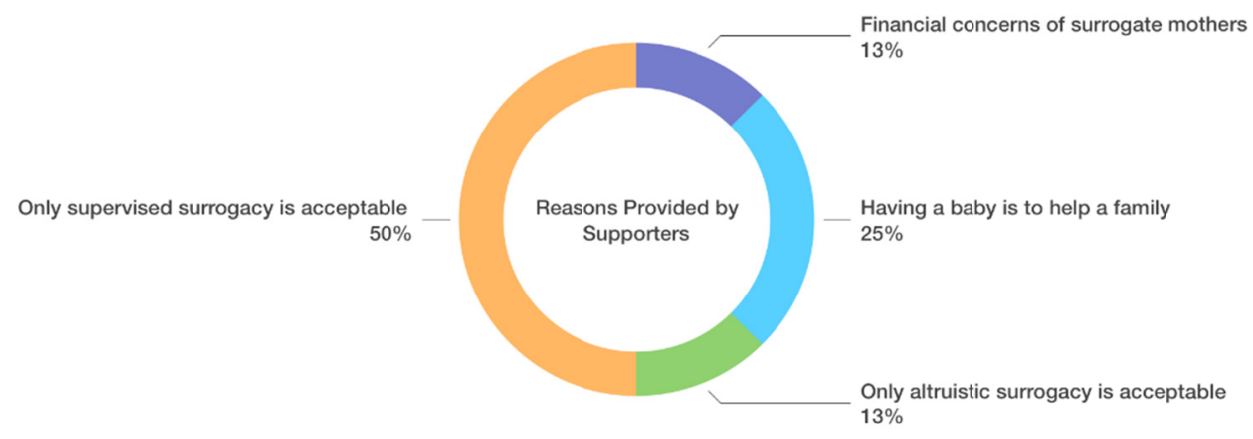

Figure 8 . Made by the author, this graph shows percentage of reasons among the 8 participants who showed support for surrogacy in the MMBang blog post

As can be seen from Figure 7 and Figure 8, half of the supporters claim that they only accept surrogacy when there is effective and well-rounded legislation in place. In other words, most consider protection for surrogate mothers and transparent transactions as crucial to the business. $25 \%$ of the supporters also emphasize the idea of a nuclear family, that two people in a relationship are not enough to form a stable family, and a child's role is pivotal and necessary. Comparatively, the conditions of surrogate mothers are not given priority among the concerns of the web users.

Among those who are against surrogacy, more gave different reasons for their opposition, as shown in the following graphs (Figure 10 and Figure 11):

Reasons Provided by Opposers

\begin{tabular}{|l|c|}
\hline REASONS FROM OPPOSITION & NUMBER OF PARTICIPANT \\
\hline $\begin{array}{l}\text { Family and Legal Confusion/ } \\
\text { Potential Problems }\end{array}$ & 8 \\
\hline Adoption as a better solution & 1 \\
\hline $\begin{array}{l}\text { Surrogacy is child trafficking } \\
\text { Having children is families' private } \\
\text { business }\end{array}$ & 6 \\
\hline $\begin{array}{l}\text { Surrogate mother is inferior } \\
\text { No reason provided }\end{array}$ & 2 \\
\hline
\end{tabular}

Figure 9. Made by the author, this graph shows reasons given among the 25 participants who demonstrated a negative attitude towards surrogacy on the MMBang blog post

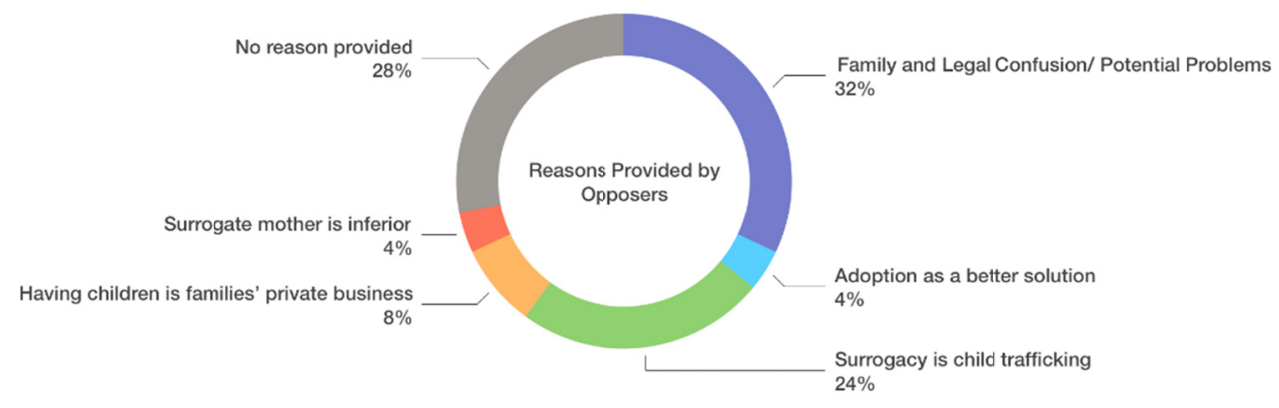

Figure 10. Made by the author, this graph shows percentages of types of reasons given by the 25 participants who are against surrogacy on the MMBang blog post

As can be seen from Figure 9 and Figure 10, about one third of the opposers are against surrogacy due to concerns about problems that might arise in the future, regarding the lack of legislative control, family relationships, and communication with the child/children. Most describe this as "a series of problems that would not be solved if a child is born from surrogacy", some say surrogacy is a "cause of family disputes and 
instability", and others are concerned that there is "no clear legislation". One fourth of the opposers describe surrogacy as a sub-category of human trafficking and therefore unethical to conduct in all cases.

As can be seen from both the supporters and the opposition, legislation is one of the primary concerns regarding public opinion toward surrogacy. While many support the cause of surrogacy as long as there is effective legislation, those who are against surrogacy also oppose it due to potential disputes, which could be solved by well-designed regulations. Following legal concerns, ethics is the second topmost focus among responders when considering acceptability of surrogacy - specifically in terms of the characterization of the child if born by a surrogate mother. Some describe surrogacy as equal to human trafficking, that being a surrogate mother is to be actively involved in the trade of children, regardless of legislation.

For those who hold a neutral opinion, 2 of the 3 responders listed both pros and cons of surrogacy and stated that they would not judge the issue based on the majoritarian societal values (which are perceived by the users as against surrogacy). The other one respondent did not provide a reason for her neutral opinion.

Overall, from the 41 total responses, we can conclude that most concerns still revolve around effective legislation and the potential problems surrogacy will lead to, either socially or ethically. All of those concerns support the conclusions found in the "Legislative practices regarding surrogacy in China" section of this paper, that most of the legal disputes revolve around "sole care" and monetary disputes. In other words, we can assume that acceptance of surrogacy will rise significantly if the laws are made as fair and ethical as possible.

Regarding the acceptability of surrogate mother as an occupation, the blog post in MMBang asked the question "If given 100,000 rmb, are you willing to serve as a surroagte mother?" The blog post received 20 responses from 18 participants. Among the 18 participants, only one of them stated that she would consider the offer if she and her family were in an extreme financial situation. Other participants say they would only accept a higher price, while others claim that they would not be a surrogate mother under any circumstances. A detailed review of the responses is provided below (Figure 11 and Figure 12):

Attitudes Regarding Being a Surrogate Mother

\begin{tabular}{|l|c|}
\hline ATTITUDES & NUMBER OF PARTICIPANT \\
\hline $\begin{array}{l}\text { Do not accept the occupation } \\
\text { under all circumstances }\end{array}$ & 7 \\
\hline $100,000 \mathrm{rmb}$ is not enough & 10 \\
\hline Others & 1 \\
\hline
\end{tabular}

Figure 11. Made by the author, this graph shows the attitudes among the 18 respondents to the MMBang blog post on surrogate mother as an occupation

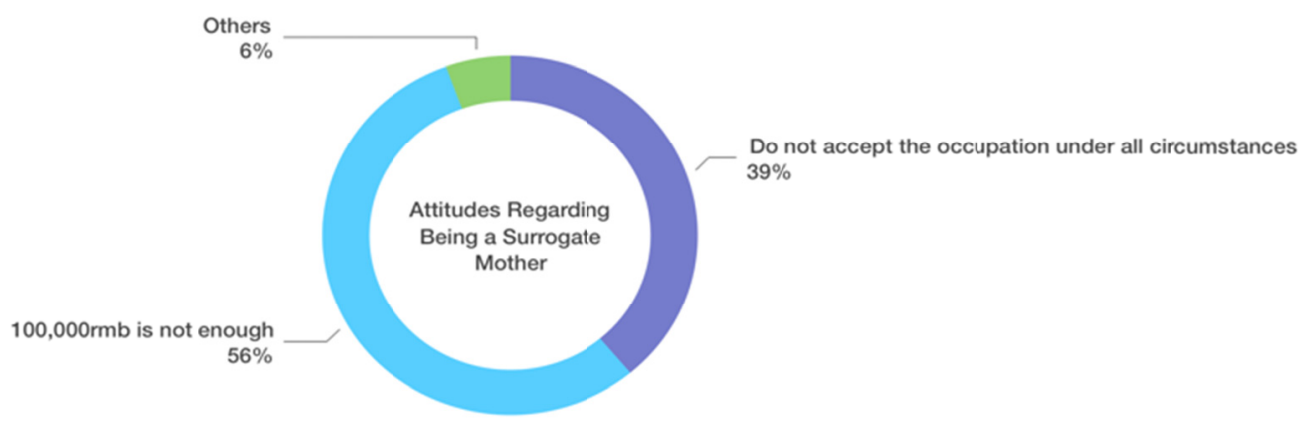

Figure 12. Made by the author, this graph shows the percentage of different types of attitudes among the 18 respondents to the MMBang blog post on the occupation of surrogate mother

While most consider surrogacy in general as unacceptable in their responses to the blog posts discussed above targeting commissioning parents, over half of the respondents gave an affirmative answer when asked whether they consider being a surrogate mother as acceptable with enough compensation. However, what sets the two 
questions (whether to accept surrogacy and whether to accept surrogate mother as an occupation) apart is the role respondents play under these two posts. In the former question, most participants imagine themselves as commissioning parents or a third party, viewing the issue from this vantage point or from a third person perspective. With such different viewpoints, those portraying themselves as commissioning parents may be more concerned about family disputes happening after surrogacy, the child's mentality, as well as legislation regarding the process of transaction and potential problems; those portraying themselves as an outsider or lawmaker, on the other hand, may think more about the issues of human trafficking, moral concerns regarding reproduction as a whole, and might conclude that surrogacy is unethical. The data obtained from the commissioning parents supports this idea that the majority of the population are against surrogacy due to concerns about potential problems. However, when respondents are compelled to imagine themselves as potential surrogate mothers, they put themselves in a position where pregnancy is for the sake of earning money, and they theoretically do not bear any legal and practical burden after giving birth to the child, while receiving relatively high pay. Considering the willingness of potential commissioning parents to accept surrogacy when dealing with infertility, as well as potential surrogate mothers willing to accept the job for its high pay, we can reach the conclusion that the supply side of the surrogacy market does exist, and surrogacy is regarded as a job with relatively high pay.

Despite societal attitudes on being a surrogate mother, in terms of opinions from surrogate mothers themselves, I was only able to find very limited information, with the majority of this limited information coming from news outlets and third party interviews, including articles from Sina News, Sohu News, and CCTV.

\subsection{Sina News}

Sina published a news article in April 2009 reporting on the status quo of surrogacy mothers in China. The report concludes that most who chose to serve as surrogate mothers are those who are struggling financially and being a surrogate mother is their last resort. Juan Wang (alias), a surrogate mother mentioned in the news article, said that to be a surrogate mother her contract included: watching TV for a maximum of one hour per day, walking in a pre-designed route with an assigned assistant nearby, accepting no visitors, and keeping her location secret. Wang was also concerned about whether the surrogacy contract was valid, and therefore she demanded pay in advance before signing the contract. ${ }^{45}$

\subsection{Sohu News}

In a news article published in February 2017, Sohu News interviewed a surrogate mother named Jialan Wang. She said that she earned $150,000 \mathrm{rmb}$ for her service and chose to be a surrogate mother because of financial burdens she had in her family. According to her, she lived in an apartment with two other surrogate mothers during her pregnancy, and during that time she was forbidden to walk around freely and tell anyone her location and could not have any visitors. ${ }^{46}$

\section{$3.6 C C T V$}

In a news article published in February 2017, a journalist pretended to be an intended commissioning parent and approached a surrogacy company. ${ }^{47}$ During the conversation, Mr. Niu, the representative of the surrogacy company, said there were essentially no women willing to be surrogate mothers in Haokou town (a town in Wuhan, a mid-sized city in China), since all women serving as surrogate mothers were in larger city areas. The surrogate mothers under their company, he also stated, usually earned 150,000 to $200,000 \mathrm{rmb}$ per deal.

Upon interviewing the surrogate mother, the journalist said that the surroagte mother's answers were brief, perhaps indicating that she was unwilling to talk more about the issue. She told the journalist that her family was informed of her decision to be a surrogate mother, and she did so for financial reasons. She said that those who failed to be a surrogate mother in her hometown would be looked down upon for not bringing money back. The report also mentions that some of the surrogate mothers were forced to abort the child once they found out that the gender of the baby did not comply with what the customer required - in such cases, the surrogate mother faced the risk of future infertility and loss of payment. ${ }^{48}$

From all of the news outlets anayzed above, it can be concluded that most surrogate mothers are not forced into

\footnotetext{
${ }^{45}$ Surrogate Mother's Very Life. Accessed August 25, 2019, http://news.sina.com.cn/c/sd/2009-04-13/145317600057_3.shtml

46 Womb Renting: China's Underground Surrogacy Industry - Souhu News. Accessed August 25, 2019, http://news.sohu.com/20170216/n480890493.shtml

${ }^{47}$ Unannounced Visit to Surrogate Mother: I Am Relying on my Body to Make Money without Success I will be mocked. Accessed August 25, 2019, http://m.news.cctv.com/2017/02/20/ARTIxzXPs0DeYi2GVRcZJDdG170220.shtml

${ }^{48}$ Unannounced Visit to Surrogate Mother: I Am Relying on my Body to Make Money without Success I will be mocked. Accessed August 25, 2019, http://m.news.cctv.com/2017/02/20/ARTIxzXPs0DeYi2GVRcZJDdG170220.shtml
} 
the business but do so because of financial burdens. They are often forced to endure human rights violations, such as not being allowed to move around freely and have visitors. Unlike the relatively large differences in the prices paid by commissioning parents, surrogate mothers often receive a fixed payment between 150 and 200 thousand rmb. At the same time, surrogate mothers usually face critical potential health risks, since most companies chose not to settle them in institutionalized hospitals due to their illegality and therefore the safety of the surrogate mothers is not ensured. Most surrogate mothers do not fully recognize the danger of becoming surrogates; even if they do, they have little power to fight back, as they themselves also voluntarily engage in an officially illegal business. This can also be seen in the low representation of surrogate mothers on the internet; companies tend to cater to the commissioning parents' needs rather than those of the surrogate mothers. Since the ultimate goal of the surrogate mother is usually the financial reward, it follows that they would also usually prioritize the needs and requirements of the customers. As a result, the surrogate mothers are largely under-represented by media and academic researchers as a whole.

For analysis on the industry of surrogacy, I refer to news articles found on both Chinese news outlets and international ones. Other than news articles, I will also discuss the official websites of companies providing surrogacy services.

\subsection{Google and Baidu}

I entered the word "surrogacy" in Chinese on both the Google search engine and the Baidu search engine and found drastically different results.

The Google search engine shows results for half a page of advertisements posted by surrogacy companies serving Chinese parents, together with a definition page of the term "surrogacy". The translated screenshot of the Google page is shown below (Figure 13):

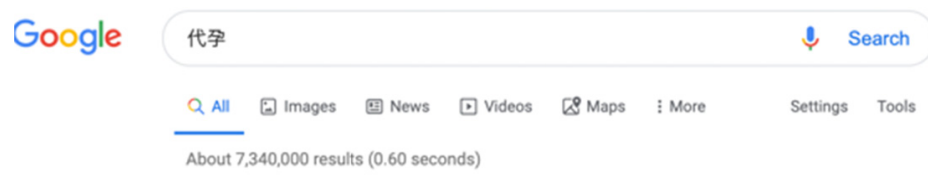

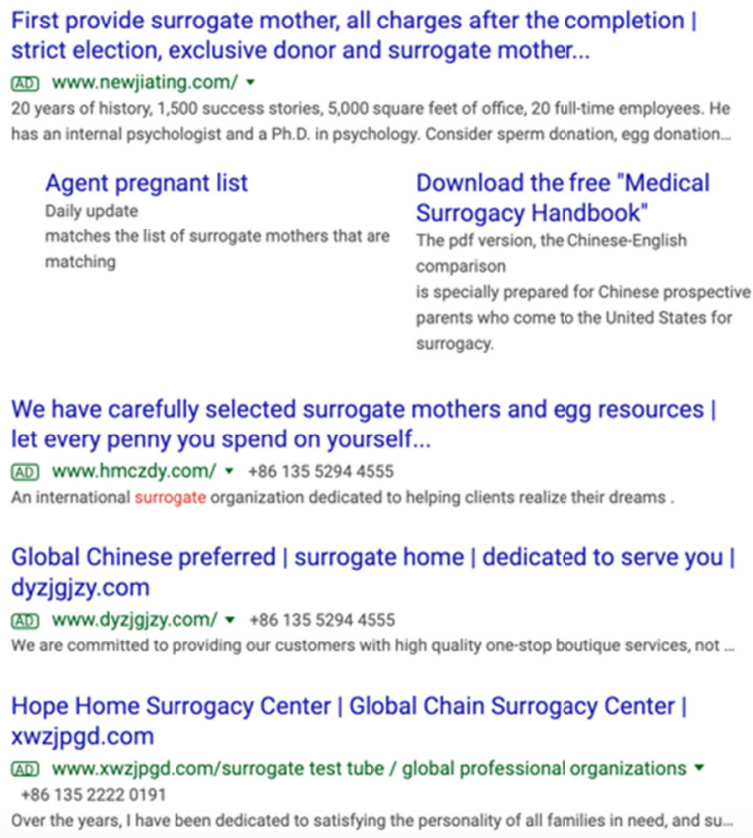

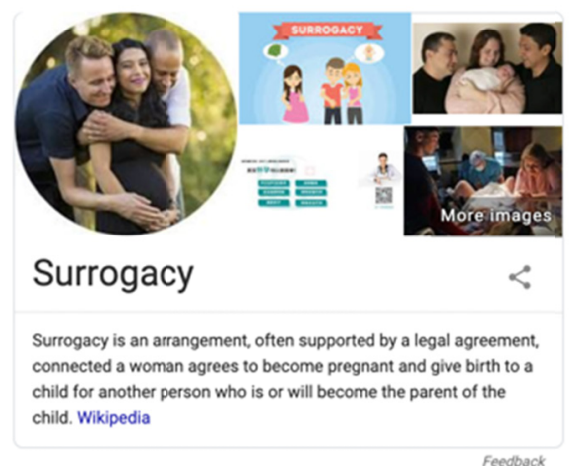
let every penny you spend on yourself. (AD) www.hmczdy.com/ v +86 13552944555

Global Chinese preferred | surrogate home | dedicated to serve you | dyzjgjzy.com

(AD) www.dyzjgjzy.com/ * +8613552944555

Hope Home Surrogacy Center | Global Chain Surrogacy Center | xwzjpgd.com

+8613522220191
Over the years, I have been dedicated to satisfying the personality of all families in need, and su.

Figure 13. Translated by Google, this page shows the search results when typing in "surrogacy" in the Google search engine in Chinese

The Baidu search result page, however, focused more on news regarding surrogacy. The original and translated screenshots of the Baidu page are shown below (Figure 14): 

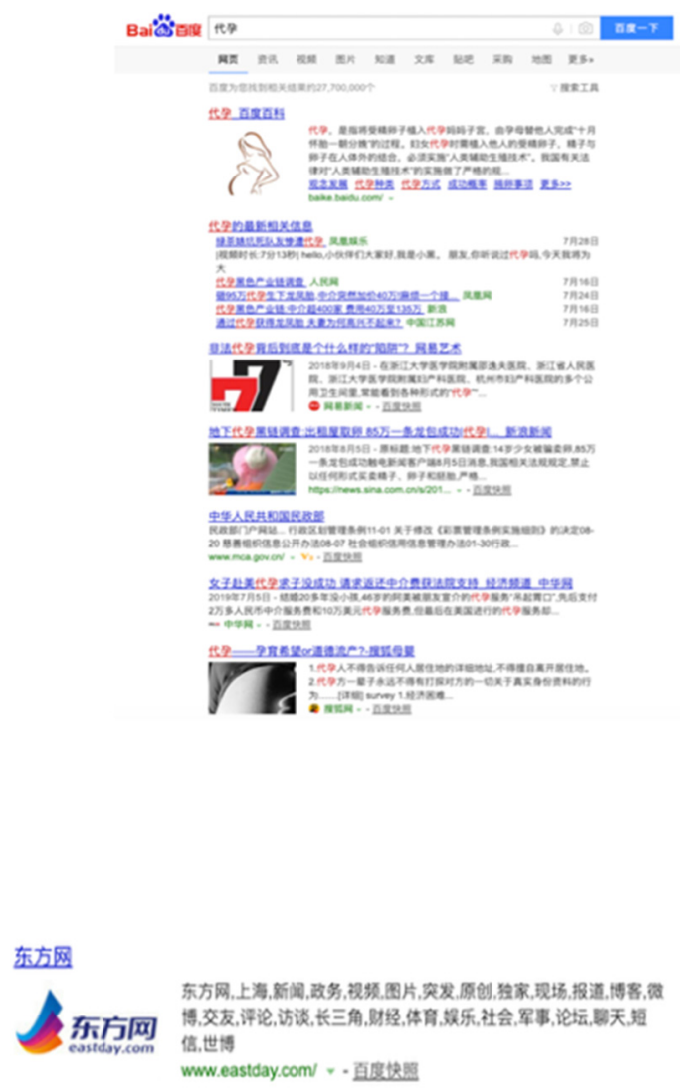

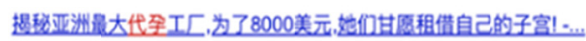

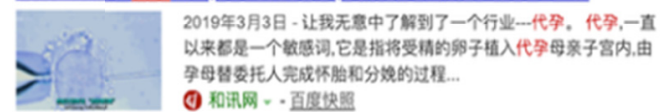

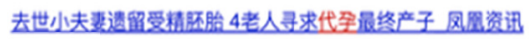
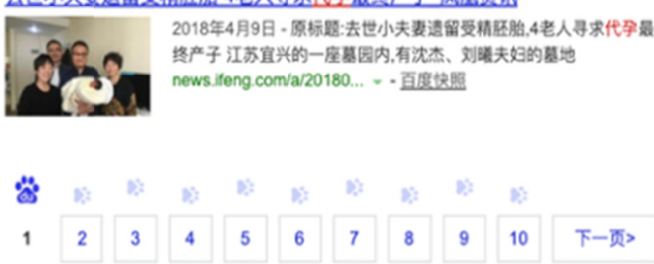
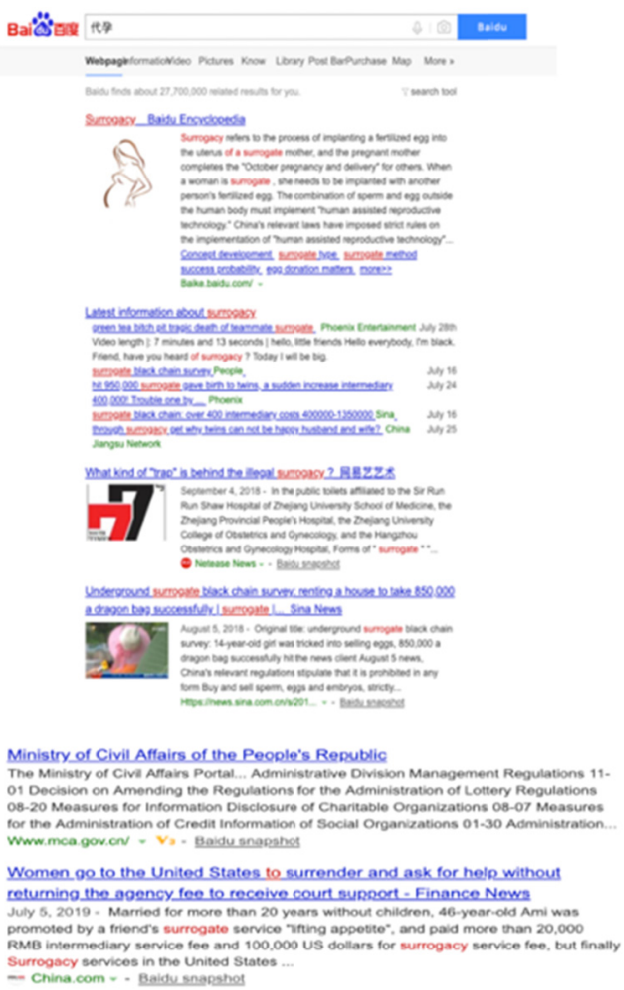

Surrogacy=gestation hope or moral abortion? - Sohu mothar and baby.

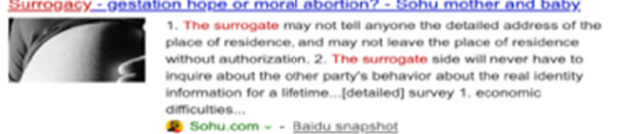

Eastern Networ

F5/ ong triange

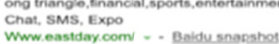

Demystifying Asia's largest surrogate factory. for the $\$ 8.000$. they are willing to rent their own uterust -

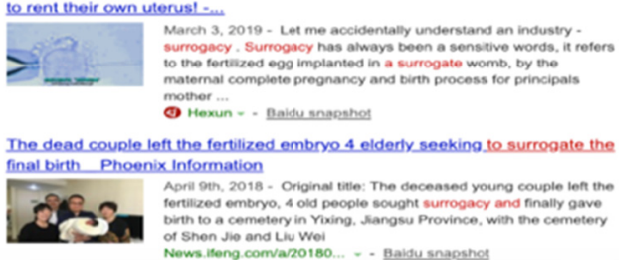

Figure 14. Translated by Google, this page shows the search results when typing in "surrogacy" in the Baidu search engine in Chinese

It can be discerned from the Baidu screenshot that the Baidu page focused more on the negatives of surrogacy, portraying it as a "moral miscarriage", "illegal", and a "black chain". On the other hand, the Google page can be seen as actively promoting surrogacy, with almost an entire page devoted to advertising the industry, portraying an image of surrogacy as completely acceptable, just as any other daily transaction. This clear distinction between an international website and a domestic one outlines the group of people that act as the demand side of surrogacy industry. Since Google is inaccessible in mainland China, most of those holding Chinese nationality would not be exposed to such advertisements; instead, the general public in China are more likely to be influenced by the mainstream media which deems surrogacy as unethical and as in a grey market. Those holding Chinese nationality while also being able to access Google are likely to be wealthier and have the financial ability to travel internationally. With all the advertisements targeting the Chinese population, it is reasonable to assume that the target customers of these advertisments are intended parents from mainland China who have the ability to see the content and respond.

I then looked at the top three websites advertising surrogacy services on the Google search engine, hoping to obtain insights about the supply side of the surrogacy market, specifically on the companies providing surrogacy services. 


\subsection{DYZJGJZY}

Titled DYZJGJZY, this company's slogan is "let love last, let family be complete", and the website says it has bases in Beijing, Tianjin, Chengdu, and Chongqing - some of the largest cities in China. On the top center of the website, the company writes: "We promise with $100 \%$ certainty that the baby will be a boy; if not a boy, we will refund all you paid., ${ }^{49}$

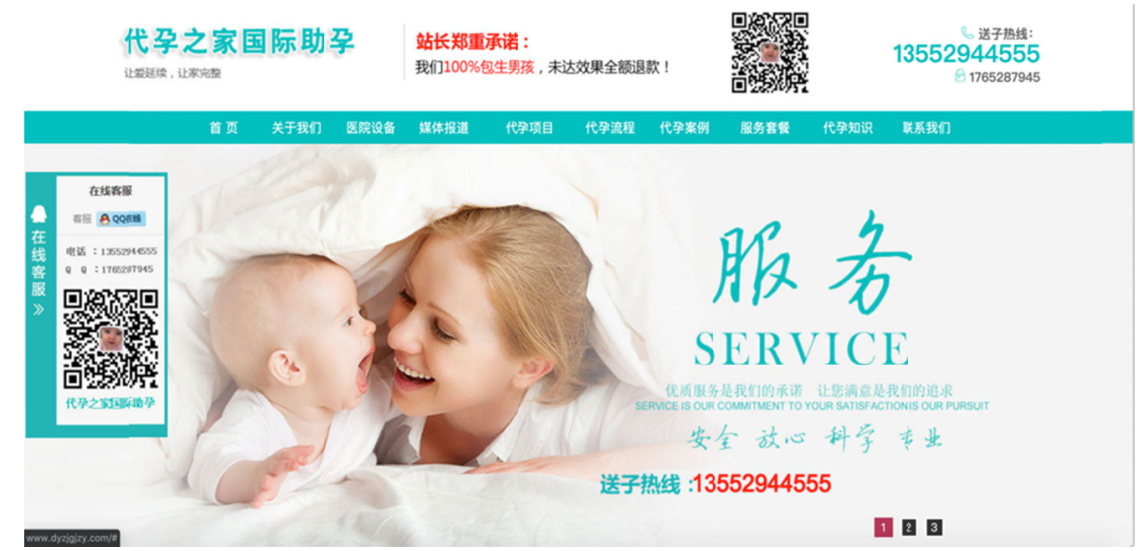

Figure 15. Screenshot of the front page of DYZJGJZY website; the screenshot was taken in July, 2019

I then looked at each tab the website provided. In the "about us" tab, the company describes itself as "a professional surrogate service institution, with many years of experience in surrogate service guidance, and provides love and surrogate services for infertile families". The company also states that it is equipped with "first-class national and qualified hospitals, charging reasonable fees" while providing eggs from college students, organizing prenatal healthcare services for surrogate mothers, conducting paternity tests, and providing birth certificates. However, though the target customers are those from mainland China and the website uses Chinese to advertise, all the pictures provided by the website portray western mothers and their children. On the surface level, the advertising pictures do not seem relatable to the intended customers at all; however, this might suggest underlying racism within the surrogacy industry, as the company also claims that it requires additional pay if the commissioning parents want the child to be born in the US so that the children can have American citizenship.

In the "hospital equipment" section, the company includes no verbal description; rather, it only posts 8 pictures, with 6 of them being lab microscopes and two of them briefly showing the entire lab. Screenshots of these pictures are provided below (Figure 16):

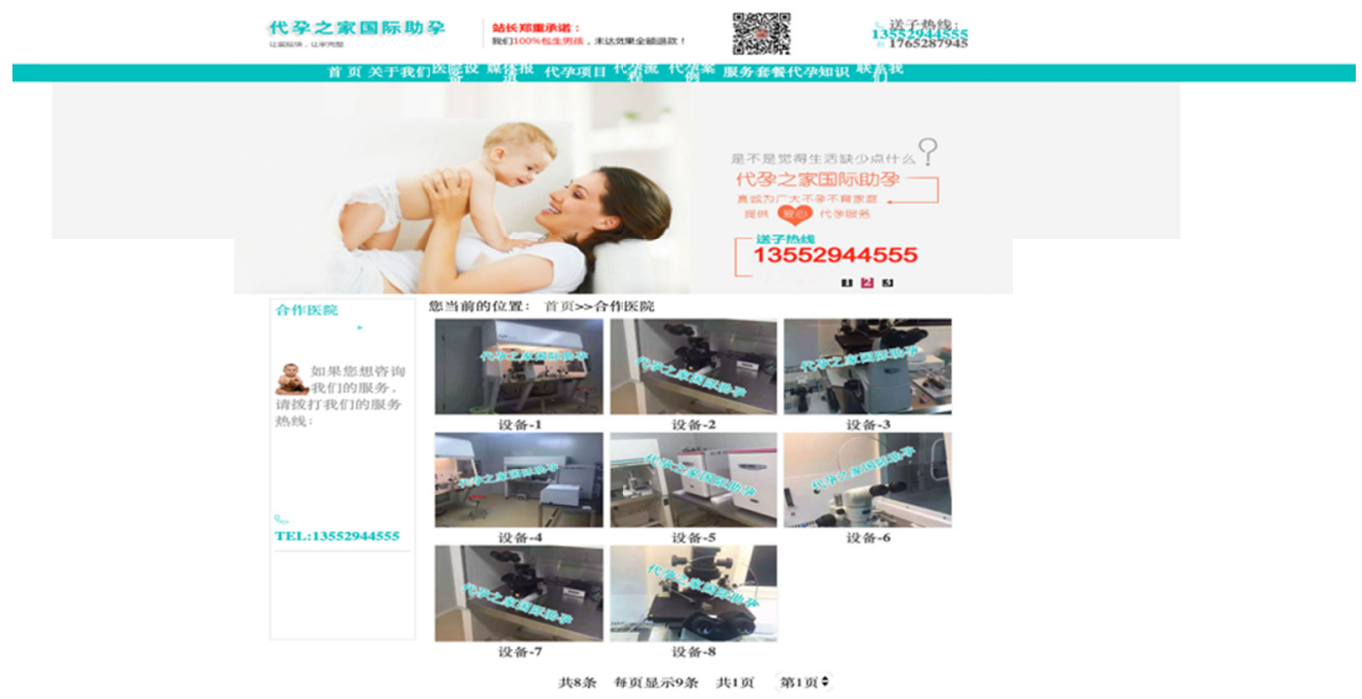

Figure 16. Screen shot of the company DYZJGJZY website "hospital equipment" section showing of lab facilities; the screenshot was taken in July, 2019

\footnotetext{
${ }^{49}$ Beijing Surrogacy, Tianjin Surrogacy, Chongqing Surrogacy, Chengdu Surrogacy. Accessed August 24, 2019, http://www.dyzjgjzy.com/.
} 
As can be seen from Figure 17, the website provides essentially no valid information on the hospital equipment. In other words, there is no guarantee that the process of surrogacy is secure and sanitary. Nevertheless, the company might have intentionally posted vague information - surrogacy in China is theoretically illegal and thus the companies cannot expose too much on lab facilities or give away information about the hospital or medical institution they use.

In the "media report" section, the company posts 10 articles regarding pregnancy as a whole, rather than specific surrogacy-related texts. All of the 10 articles were posted between March 19 and 20, 2018. Again, the content doesn't concern surrogacy but rather talks about pregnancy in general and thus is irrelevant to Chinese commissioning parents. The company might have intentionally done this to get around existing legislation.

In the "surrogate program" section, the company provides 4 options, illustrating that the commissioning parents can choose whether to assign gender, whose egg/sperm to use, whether the baby is to be carried by the intended mother or the surrogate mother, and whether the child needs a United States passport. In the "surrogate process" section, the website outlines the process of the surrogate mother's impregnation. The process, compared to other sections of the website, is much more detailed and well explained; however, the company does not discuss its practices during the surrogate mother's pregnancy. The translated screenshot of this section is shown below (Figure 17):

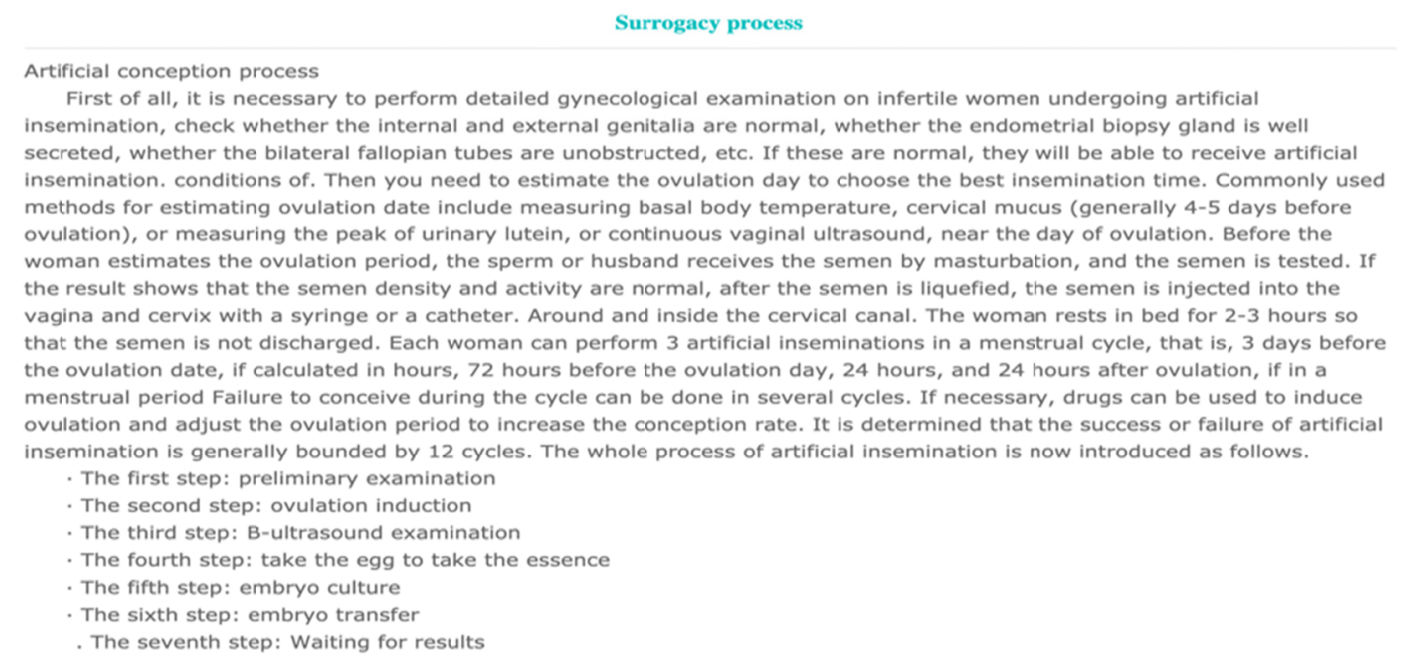

Figure 17. Translated into English from Chinese by Google, this page is a screenshot of DYZJGJZY's website description in its "surrogate program" section of surrogacy procedures conducted by the company, in which the precedure of surrogacy is roughly depicted

In the "surrogacy case" section, the company posted 6 pictures of what it describes as successful surrogacies. Among the 6 pictures, 3 are twins, 1 is a quadruplet, and 2 are single children. In the "surrogacy package" section, the company outlines 4 possible packages prospective customers can choose from, with the prices of $300,000 \mathrm{rmb}, 350,000 \mathrm{rmb}, 600,000 \mathrm{rmb}$, and $900,000 \mathrm{rmb}$. The difference between the four packages includes whether the commissioning parents can choose gender of the child and the amount of time the customer needs to be involved in the process. In the "surrogacy knowledge" section, the website essentially repeats the content that appears in the "media report" section, with the contents being irrelevant to surrogacy. In the "contact us" section, the company leaves its information on WeChat and QQ (a Chinese social media service that functions like a combination of Snapchat and Instagram), and a phone number.

Overall, the information provided by the website includes no contextual evidence that the company has been successful in its surrogacy services, and there does not seem to be a guarantee that the process is safe, both for the surrogate mother and financially for the commissioning parents. The life and role of the surrogate mother is barely mentioned; in other words, the living conditions and basic rights of surrogate mothers are not ensured. What's more, much of the information the company provides is illegal and implicitly sexist; gender testing has been long outlawed in China and parents are not allowed to be told the gender of a baby before its birth. ${ }^{50}$ The pictures of successful surrogacy also favor those who gave birth to more babies and those who gave birth to boys

${ }^{50}$ Jing-Bao Nie. (February 2010). Limits of State Intervention in Sex-Selective Abortion: The Case of China. Culture, Health \& Sexuality, $12,205$. 
rather than girls. According to a company leader from Guangzhou, most of the parents who chose to specify the gender of their child would choose to have a boy. ${ }^{51}$ The company, by advertising itself as being able to give birth to boys and those with a foreign nationality, indicates the sexist and racist implications of the industry. With regard to current legislation and considering the price of surrogacy as indicated on the website, 3,000 rmb as penalty for engaging in surrogacy is at most one third of the price. Thus, it is reasonable to conclude that current legislation does not function as a deterrent to surrogacy because the illegal profits far outweigh the penalties.

\subsection{Beijing International Surrogacy Company}

Based in Beijing, this surrogacy company is essentially the same as DYZJGJZY in terms of its website. Both of them are divided into the same number of sections with the same names, provide the same options for customers to choose from, and the impregnation process described on the two websites are exactly the same. The only difference in the website information is that the Beijing International Surrogacy Company provides details of action during the pregnancy process. One thing to note is that the company specifically stresses that after the surrogacy is confirmed as successful, "the commissioning parents and the company are to destroy the contract and all other materials". In other words, if there are further disputes regarding the surrogacy afterwards, there is no way for any actor in the transaction to trace any record of it, and no legal protection is then going to be ensured. This also highlights that the company knows surrogacy is currently technically illegal in China, but they are still advovating for this business. The fact that they explicitly state to "destroy the contract" proves the inefficacy of current surrogacy legislation.

\subsection{Conceptual Parents}

Based in San Diego and Los Angeles, California and founded in 1999, Conceptual Parents appears to be a company targeting customers from around the world. According to the company's website, they are dedicated to being "infertility consultants" instead of "brokers or a matching service". 52 The website can be translated into Chinese, English, German, and Spanish, with flags exhibited on the top of the page for the US, China, Hongkong, Taiwan, Germany, and Spain. A screenshot of the web page is shown below (Figure 18):

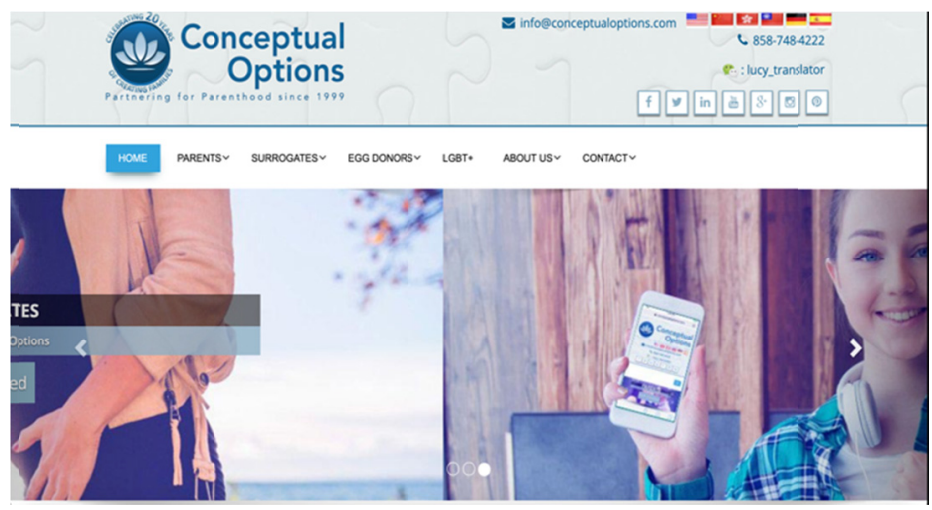

Figure 18. Screenshot of the English version of the company Conceptual Options website front page; the screenshot was taken in July, 2019

In this paper, I will focus solely on the Chinese version of the website, in order to gain insights into how the international surrogacy market caters to China and influences Chinese society. On the front page of the website, the company specifically outlines that surrogacy is "supported and protected by Californian law", and sub-categorizes the site into "parents", "surrogates", "egg donors", "about us", "contact us", and "new information" sections. It should be noted that there isn't a tab called "LGBT+" on the Chinese site like there is on the English, Spanish, and German ones. However, there is a hyperlink attached to the homepage that states "for same sex couples", with detailed information and guidance within. Compared with the DYZJGJZY and Beijing International Surrogacy Company websites, Conceptual Parents details much of the surrogacy process and gives users access to apply for a surrogate mother or egg donor on the website. The company also posts information about surrogate mothers on the site, including first name, age, region, and past experiences on serving as surrogate mother; a Google-translated screenshot is shown below (Figure 19):

\footnotetext{
51 "Womb Renting: the Underground Market in China's Surrogacy Industry" accessed August 25, 2019, http://news.sohu.com/20170216/n480890493.shtml.

52 "Infertility Consultants in San Diego and Los Angeles," Conceptual Options (blog), accessed August 25, 2019, https://www.conceptualoptions.com/our-philosophy/.
} 


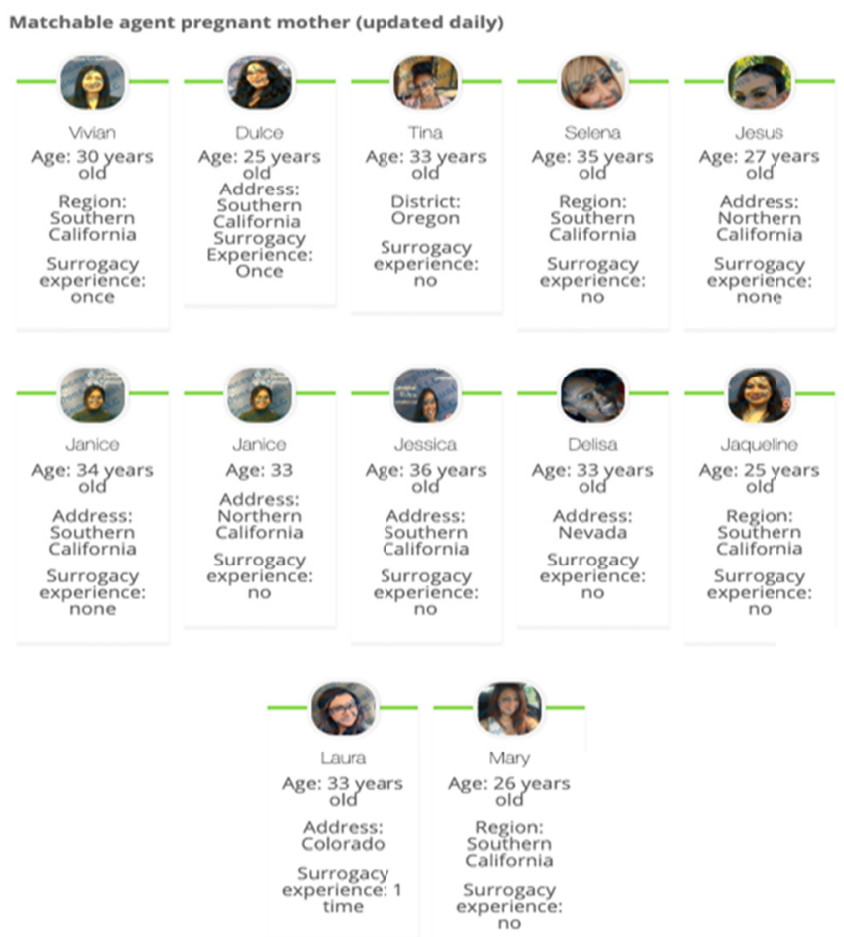

Figure 19. Translated from Chinese to English by Google, this webpage shows information about surrogate mothers working for Conceptual Parents, including their name, age, region, and past experiences

In addition to the above information, Conceptual Parents also makes certain commitments on caring for the surrogate mothers, with basic criteria for applying to be a surrogate mother (e.g. has had healthy fertility experiences), and states that the process of picking a surrogate mother is one of mutual selection - there is no dominant party within the relationship. ${ }^{53}$

Still, Conceptual Parents offers the choice of having the baby born in the US and thus having the opportunity for American citizenship, but the company doesn't specify the payment under any surrogacy options.

Based on the website, Conceptual Parents looks the most professional among the three websites discussed, with better human rights protection mechanisms and more transparent procedures regarding the surrogacy process itself. There may be many different reasons behind this: among the three companies discussed in this paper, Conceptual Parents has the largest scale and influence (considering its intended customers have international backgrounds) and thus bears greater liability when considering legal issues. Conceptual Parents is also the only company discussed that is based in a place where surrogacy and same sex marriage are legal and has well-established legislation concerning such transactions. Conceptual Parents is also the oldest of the three companies and thus has more experience with different cases on surrogacy.

Overall from this overview on these three companies it can be seen that legislation is still key. With relatively vague legislation upon surrogacy, the law leaves spaces for profit-driven companies to exploit and creates a completely unregulated free market system where discrimination including racism and sexism can emerge. On the other hand, when there are clearly defined rules on surrogacy, it is easier for businesses to follow the set letter of the law, not only for a fair environment in which companies can compete, but also for a safer and institutionalized surrogacy process.

\section{A Brief Overview: Surrogacy in China}

Feminist scholar Andrea Whittaker categorizes ethical concerns regarding transnational surrogacy into eight groups: the manipulation of custodian rights to favor the surrogacy trade (legislation, or loopholes in legislation, tend to be exploited by the wealthy), questions over the quality and conditions of surrogate care, the limits of medical care for surrogates post-delivery, the practice of embryo transfers and selective reduction (important in terms of gender discrimination, where girls are more likely to be aborted than boys), the lack of medical advocates for surrogates since clinics compete for business profits, and the issue of free choice within conditions

53 “Our Agent Pregnant Mothers | Conceptual Options Surrogacy and Egg Donation Center,” accessed August 25, 2019, https://www.newjiating.com/our-surrogates/. 
of economic coercion. ${ }^{54}$

Taking into account the existence of gender bias, surrogacy as a new industry, and the ineffective legislation, these challenges remain issues when it comes to analyzing surrogacy and public opinions regarding surrogacy in the Chinese market. In terms of public opinions, most people oppose the idea of surrogacy as a business. Even when viewing the issue from the perspective of commissioning parents, most still prefer surrogacy to be illegal in order to prevent future conflicts, either monetary or ethical. However, most people also consider reproduction to be a pivotal part of life and having a child to be a necessary experience; with such concerns, many infertile couples are then trapped in the dilemma of wanting to have children and resorting to commercial surrogacy. Most choose to support commercial surrogacy in such cases. When asked to view themselves as potential surrogate mothers, the general public, contrary to the negative perspective on surrogacy in the previous case, mostly chooses to accept the occupation but demand much higher pay than currently offered in the surrogacy market. As can be seen from the responses posted on multiple mommy blogs, regardless of surrogacy being illegal in China, the general public is not completely against the idea of surrogacy; while most consider it unethical and that it should serve as a last resort, they are also willing to embrace surrogacy when considering cases of infertility. In addition, while the occupation of surrogate mother is not generally seen as a respected job, it is acceptable to most.

In terms of the industry, most accessible surrogacy companies in China are locally based, and their target customers are wealthy citizens. Most of the local surrogacy companies fail to provide details about their services on their websites and understand that the business they are conducting is illegal. In contrast, international surrogacy companies may tend to charge higher prices but provide more accessible information on the detailed procedures and safety concerns of surrogacy. The local surrogacy companies also show sexist and racist tendencies by providing services that favor one gender or race over the other.

With regards to surrogate mothers, people in this line of work are very under-represented in terms of media exposure and general information online. Most of the reports focus on individual life stories of surrogate mothers; there is very little data and systematic research on this population. From the reports discussed in this paper, we can see that surrogate mothers are generally portrayed as entering the industry for financial reasons, that they do so without many safety, healthcare, and insurance procedures in place, and that their rights to autonomy and privacy are infringed upon during their pregnancy. Surrogate mothers are easily exploited due to their unfamiliarity with reproduction technologies and poorly followed consent procedures. Nevertheless, despite knowing these facts, more woman are willing to be surrogate mothers in poverty-hit regions, as surrogacy is one of the easiest and quickest ways for a woman to obtain money in these circumstances. As a result, the supply side of the surrogacy market is sufficient enough for businesses to operate, just as the demand side is increasing due to the rising infertility rate, the cultural narrative of seeing having children as necessity, and the revocation of one-child policy.

It seems that the most prevalent concern around surrogacy in China is the lack of clear legislation, both economically and in terms of ethic issues. While the current surrogacy market operates in a lasseiz-faire model without much effective government supervision, the general public view seems to be that people would accept the idea of surrogacy if there were well-established regulations on the demand side. On the supply side, most surrogate mothers are vulnerable to human rights violations committed by third parties, which could also be solved to a great extent by effectively enforcing laws.

\section{References}

[News on Trend] How do you view the surrogacy industry? MMBang in Suzhou_MMBang. Retrieved August 24, 2019, from https://www.mmbang.com/suzhou/bang/6872673\#comment_enter

About MMBang_MMBang. Retrieved August 24, 2019, from https://www.mmbang.com/about/about

Beijing Surrogacy, Tianjin Surrogacy, Chongqing Surrogacy, Chengdu Surrogacy. Retrieved August 24, 2019, http://www.dyzjgjzy.com/

Can you accept surrogacy? Women's mood_Forum_PCBaby. Retrieved August 24, 2019, https://bbs.pcbaby.com.cn/topic-371782.html

Ding, C. Y. (January 8, 2015).Surrogacy Litigation in China and Beyond. Journal of Law and Biosciences, 33-55. https://doi.org/10.1093/jlb/lsu036

Howard, S. (October 20, 2014). Taming the International Commercial Surrogacy Industry. British Medical

${ }^{54}$ Whittaker, Merit and Money: The Situated Ethics of Transnational Commercial Surrogacy in Thailand, 101. 
Journal, 349, 3. https://doi.org/10.1136

Hu, Y. (2016). Family and Gender Values in China: Generational, Geographic, and Gender Differences. Journal of Family Issues, 37(9), 26. https://doi.org/10.1177/0192513X14528710

Human Assisted Reproductive Technology Management Measures. Retrieved August 25, 2019 from $\mathrm{http}: / / \mathrm{www} . \mathrm{gov} . \mathrm{cn} / \mathrm{fwxx} / \mathrm{bw} / \mathrm{wsb} /$ content_417654.htm

Introduction - PCbaby - Pacific Online. Retrieved August 24, 2019, from https://corp.pconline.com.cn/english/index-baby.htm

Li, M. L. (2017). The Analysis of Surrogate Dispute in Our Country. Guangdong University of Finance and Economics.

Liu, M. (May 2019). On the Judicial Validity of Surrogacy Contracts - from the Perpective of Jeremy Bentham's Utilitarianism (pp. 20-22).

National People's Congress. General Principles of the Civil Law of the People's Republic of China. General Principles of the Civil Law of the People's Republic of China, April 12, 1986. Retrieved from http://www.china.org.cn/china/LegislationsForm2001-2010/2011-02/11/content_21898337.htm

Nie, J.-B. (February 2010). Limits of State Intervention in Sex-Selective Abortion: The Case of China. Culture, Health \& Sexuality, 12, 205-219.

Our Agent Pregnant Mothers | Conceptual Options Surrogacy and Egg Donation Center. Retrieved August 25, 2019, from https://www.newjiating.com/our-surrogates/

Peng, Y. S. (November 2010). When Formal Laws and Informal Norms Collide: Lineage Networks versus Birth Control Policy in China. The University of Chicago Press, 3(116), 770-805.

Potts, M. (August 19, 2006). China's One Child Policy. British Medical Journal, 33(7564), 361-362.

Raposo, V. (2017). Surrogacy in Greater China: The Legal Framework in Taiwan, Hong Kong, Macao, and Mainland China. Pacific Basin Law Journal, 34(2), 136-147.

Serene. J. (Spring 2013). Intersectionality and the Ethics of Transnational Commercial Surrogacy. International Journal of Feminist Approaches to Bioethics, 6, 68-90.

Surrogacy, is it feasible and legal? Women's Mood_Forum_PCBaby. Retrieved August 24, 2019, from https://bbs.pcbaby.com.cn/topic-569003.html

Surrogate Mother's Very Life. Retrieved August 25, 2019, http://news.sina.com.cn/c/sd/2009-04-13/1453176 00057_3.shtml

The Ministry of Health. Human Assisted Reproductive Technology Management Measures. Human Assisted Reproductive Technology Management Measures. Retrieved July 26, 2019, from http://www.gov.cn/fwxx/bw/wsb/content_417654.htm

Unannounced Visit to Surrogate Mother: I Am Relying on the Body to Make Money without Success Will Be Jokes. Retrieved August 25, 2019, from http://m.news.cctv.com/2017/02/20/ARTIxzXPs0DeYi2GVRcZJD dG170220.shtml

Van Niekerk, A. (December 1995). The Ethics of Surrogacy: Women's Reproductive Labour. Journal of Medical Ethics, 21, 345-349.

Whittaker, A. (Fall 2014). Merit and Money: The Situated Ethics of Transnational Commercial Surrogacy in Thailand. International Journal of Feminist Approaches to Bioethics, 7, 100-120.

Winddance Twine, F. (2015). Outsourcing the Womb: Race, Class, and Gestational Surrogacy in a Global Market (2nd ed.). 711 Third Avenue, New York, NY 10017: Routledge.

Womb Renting: China's Underground Surrogacy Industry - Souhu News. Retrieved August 25, 2019, from http://news.sohu.com/20170216/n480890493.shtml

Yan, A. (April 3, 2017). Why China Keeps Surrogacy a Grey Area.

\section{Copyrights}

Copyright for this article is retained by the author(s), with first publication rights granted to the journal.

This is an open-access article distributed under the terms and conditions of the Creative Commons Attribution license (http://creativecommons.org/licenses/by/4.0/). 